\title{
Ketamine for suicidal ideation
}

New trial challenges current thinking about ketamine

Riccardo De Giorgi, ${ }^{12}$ Wellcome Trust doctoral training fellow

${ }^{1}$ University of Oxford, Department of Psychiatry, Warneford Hospital, Oxford, UK

${ }^{2}$ Oxford Health NHS Foundation Trust, Warneford Hospital, Oxford, UK

riccardo.degiorgi@psych.ox.ac.uk

Research, doi:10.1136/bmj-2021-067194

The repurposing of ketamine for use in mental disorders is a noteworthy yet disputed development in psychiatry over the past two decades. ${ }^{12}$ Ketamine has an antidepressant effect that is unconventionally swift and that does not apparently involve monoaminergic pathways. ${ }^{3}$ Ketamine could also rapidly reduce suicidal ideation in a way that is at least partially independent from its effect on mood. ${ }^{4}$

Current treatments for people with acute suicidal ideation are unsatisfactory. ${ }^{5}$ Holistic approaches involving psychosocial interventions, patient and family education, and hospital admission or community based management with close monitoring are currently the key interventions. However, these strategies might demand weeks of support and are limited by availability of resources. Although only a minority of patients with suicidal ideation go on to attempt suicide, ${ }^{6}$ many patients experience extreme suffering during emergency presentations. It would therefore be difficult to argue against any new treatment if it were shown to be effective, safe, fast acting, and readily available.

In this context, the linked study by Abbar and colleagues (doi:10.1136/bmj-2021$067194)^{7}$ is set to challenge some of our current insights about ketamine. This randomised placebo controlled trial investigated the anti-suicidal effects of intravenous ketamine from three days to six weeks after treatment in 156 patients voluntarily admitted to hospital with severe suicidal ideation. Underlying diagnoses were divided into three main groups: bipolar disorder, depressive disorder, or other psychiatric disorders.

This relatively large, well characterised study population adds to the findings of several previous trials. ${ }^{8}$ The use of specific scales measuring suicidality is a further methodological strength. The main limitation is that Abbar and colleagues compared ketamine against saline infusions (as did most trials in 2013 when their trial was conceived), while more recent studies have used midazolam as the comparator ${ }^{9}$; therefore, masking could have been affected by recognisable acute effects associated with ketamine, such as depersonalisation. 
The authors found a significant difference in remission of suicidal ideation favouring ketamine at day three after treatment (odds ratio 3.68, 95\% confidence interval 1.90 to 7.30), which became non-significant by week 6 owing to good improvement in both groups. These observations replicate previous findings. ${ }^{8}$ However, ketamine's beneficial effect was driven almost exclusively by patients with bipolar disorder (odds ratio 14.1, 95\% confidence interval 3.0 to 92.2$)$. Benefits were not observed in those with major depression $(\mathrm{P}=0.6)$ or other mental illnesses $(\mathrm{P}=0.07)$. Notably, no new manic or psychotic symptoms were reported.

This unexpected outcome perhaps defies the prevailing notion that patients with major depression would benefit most from ketamine. In fact, both usual care and ketamine given with usual care led to low, comparable remission rates of $35.7 \%$ and $42.3 \%$ for suicidal ideation, respectively, in patients with depressive disorder. While this study therefore confirms that many patients with depressive disorder and suicidal ideation remain poorly served by available treatments, it shows that another important group of patients with acute suicidal ideation, those with bipolar disorder, could benefit from ketamine. Once again, here is evidence that careful clinical evaluation must precede any consideration of ketamine use, which must be reserved for specific clinical presentations and not given indiscriminately to anyone presenting with suicidal thoughts. ${ }^{10}$

Abbar and colleagues report a mediating effect of mental pain on ketamine's anti-suicidal properties, which further hints that mechanisms other than N-methyl-D-aspartate modulation, ${ }^{11}$ possibly involving opioid receptor antagonism, ${ }^{12}$ can regulate the action of ketamine on suicidal ideation. Overall, their results suggest that the of suicidality embraces complex biological as well as psychological factors - and that these factors can vary between mental disorders. Their findings are also a clear reminder that suicidal people present to healthcare services because they are in unbearable pain. If rapid analgesia is provided routinely for somatic pain, should the same option be available for acute mental pain? ${ }^{13}$ The possibility of an opioid related mechanism of action for ketamine signals a need for caution, as well as restrictions on the duration of treatment.

This important trial was conceived in 2013, conducted between 2015 and 2019, and is only now being published. During this long gestation, newly synthesised esketamine has been approved for the treatment of resistant depression (not without criticism) by most international regulators. ${ }^{14} 15$

Trials of ketamine still matter, however. Firstly, esketamine trials have not been able to fully replicate the positive findings on suicidality reported for ketamine. ${ }^{16}$ Although this might change, ${ }^{17}$ it raises the possibility that these two compounds have distinct 
pharmacological activity profiles, and therefore underlying distinct clinical effects. ${ }^{11}$

Secondly, industry led development and testing of new drugs should not hold back research into older but still valuable molecules such as ketamine and other non-conventional drugs (including hallucinogens). ${ }^{18}$

Will ketamine be given to eligible patients with suicidal ideation any time soon? This is hard to say, given the plausible concern that the widespread use of ketamine might trigger a new opioid style crisis. ${ }^{10}$ Whether ketamine reduces suicidal ideation in some people is a matter of evidence - which this trial by Abbar and colleagues provides. ${ }^{7}$ But whether the emergency use of ketamine for suicidal crises will be recommended in practice depends on many other factors, including the values and preferences of patients, clinicians, researchers, and policymakers.

I am grateful to Philip J Cowen, professor of psychopharmacology at the Department of Psychiatry, University of Oxford, Oxford, UK, for his advice and support.

Competing interests: The BMJ has judged that there are no disqualifying financial ties to commercial companies. The authors declare the following other interests: None.

Further details of The BMJ policy on financial interests is here:

https://www.bmj.com/sites/default/files/attachments/resources/2016/03/16-current-bmjeducation-coi-form.pdf.

Provenance and peer review: Commissioned; not externally peer reviewed.

$<$ jrn $>1 \quad$ Kraus C, Wasserman D, Henter ID, Acevedo-Diaz E, Kadriu B, Zarate CA Jr. The influence of ketamine on drug discovery in depression. Drug Discov Today

2019;24:2033-43. doi:10.1016/j.drudis.2019.07.007. PubMed</jrn>

$<$ jrn $>2$ Newport DJ, Schatzberg AF, Nemeroff CB. WHITHER KETAMINE AS AN ANTIDEPRESSANT: PANACEA OR TOXIN? Depress Anxiety 2016;33:685-8. doi:10.1002/da.22535. PubMed $</$ jrn $>$

$<$ jrn>3 McIntyre RS, Rosenblat JD, Nemeroff CB, et al. Synthesizing the Evidence for Ketamine and Esketamine in Treatment-Resistant Depression: An International Expert Opinion on the Available Evidence and Implementation. Am J Psychiatry 2021;178:383-99. doi:10.1176/appi.ajp.2020.20081251. PubMed</jrn>

$<$ jrn>4 Wilkinson ST, Ballard ED, Bloch MH, et al. The Effect of a Single Dose of Intravenous Ketamine on Suicidal Ideation: A Systematic Review and Individual Participant Data Meta-Analysis. Am J Psychiatry 2018;175:150-8. doi:10.1176/appi.ajp.2017.17040472. PubMed $</$ jrn $>$

$<$ jrn $>5$ Zalsman G, Hawton K, Wasserman D, et al. Suicide prevention strategies revisited: 10-year systematic review. Lancet Psychiatry 2016;3:646-59. doi:10.1016/S22150366(16)30030-X. PubMed</jrn>

<jrn>6 Klonsky ED, Dixon-Luinenburg T, May AM. The critical distinction between suicidal ideation and suicide attempts. World Psychiatry 2021;20:439-41. doi:10.1002/wps.20909. PubMed </jrn>

$<$ jrn $>7$ Abbar M, Demattei C, El-Hage W, et al. Ketamine for the acute treatment of severe suicidal ideas: double blind, randomised placebo controlled trial. BMJ 2022;376:e067194. doi:10.1136/bmj-2021-067194.</jrn> 
$<$ jrn $>8 \quad$ Witt K, Potts J, Hubers A, et al. Ketamine for suicidal ideation in adults with psychiatric disorders: A systematic review and meta-analysis of treatment trials. Aust NZJ Psychiatry 2020;54:29-45. doi:10.1177/0004867419883341. PubMed</jrn>

$<$ jrn>9 Grunebaum MF, Galfalvy HC, Choo TH, et al. Ketamine for Rapid Reduction of Suicidal Thoughts in Major Depression: A Midazolam-Controlled Randomized Clinical Trial. Am J Psychiatry 2018;175:327-35. doi:10.1176/appi.ajp.2017.17060647.

$\underline{\text { PubMed }}</$ jrn $>$

$<$ jrn $>10$ George MS. Is There Really Nothing New Under the Sun? Is Low-Dose Ketamine a Fast-Acting Antidepressant Simply Because It Is An Opioid? Am J Psychiatry 2018;175:1157-8. doi:10.1176/appi.ajp.2018.18070800. PubMed</jrn>

$<$ jrn>11 Jelen LA, Young AH, Stone JM. Ketamine: A tale of two enantiomers. $J$ Psychopharmacol 2021;35:109-23. doi:10.1177/0269881120959644. PubMed</jrn>

$<$ jrn $>12$ Williams NR, Heifets BD, Bentzley BS, et al. Attenuation of antidepressant and antisuicidal effects of ketamine by opioid receptor antagonism. Mol Psychiatry 2019;24:1779-86. doi:10.1038/s41380-019-0503-4. PubMed</jrn>

$<$ jrn>13 Conejero I, Olié E, Calati R, Ducasse D, Courtet P. Psychological Pain, Depression, and Suicide: Recent Evidences and Future Directions. Curr Psychiatry Rep 2018;20:33. PubMed doi:10.1007/s11920-018-0893-z</jrn>

$<$ jrn>14 Kim J, Farchione T, Potter A, Chen Q, Temple R. Esketamine for TreatmentResistant Depression - First FDA-Approved Antidepressant in a New Class. $N$ Engl J Med 2019;381:1-4. doi:10.1056/NEJMp1903305. PubMed</jrn>

$<\mathrm{jrn}>15$ Mahase E. Esketamine is approved in Europe for treating resistant major depressive disorder. BMJ 2019;367:17069. doi:10.1136/bmj.17069. PubMed $</ j r n>$

$<$ jrn>16 Siegel AN, Di Vincenzo JD, Brietzke E, et al. Antisuicidal and antidepressant effects of ketamine and esketamine in patients with baseline suicidality: A systematic review. J Psychiatr Res 2021;137:426-36. doi:10.1016/j.jpsychires.2021.03.009. PubMed</jrn>

$<$ jrn>17 Xiong J, Lipsitz O, Chen-Li D, et al. The acute antisuicidal effects of singledose intravenous ketamine and intranasal esketamine in individuals with major depression and bipolar disorders: A systematic review and meta-analysis. J Psychiatr Res 2021;134:5768. doi:10.1016/j.jpsychires.2020.12.038. PubMed</jrn>

$<$ jrn>18 De Gregorio D, Aguilar-Valles A, Preller KH, et al. Hallucinogens in Mental Health: Preclinical and Clinical Studies on LSD, Psilocybin, MDMA, and Ketamine. $J$ Neurosci 2021;41:891-900. doi:10.1523/JNEUROSCI.1659-20.2020. PubMed</jrn> 